\title{
Influence of Strain Rate and Temperature on the Creep of Cold-Drawn Ingot Iron
}

\author{
By William D. Jenkins and Thomas G. Digges
}

\begin{abstract}
A study was made of the effects of variations in both strain rate and temperature on the creep characteristics in tension of cold-drawn ingot iron. The third stage of creep began without necking or without the presence of cracks of microscopic dimensions, but considerable necking occurred in all specimens tested to fracture. The resistance to creep in the second stage and the resistance to fracture increased as the test temperature was decreased. The stress required to initiate fracture also increased as the strain rate increased. The general trend was for the ductility at fracture to increase with an increase in the strain rate and the plastic extension at fracture to decrease with an increase in temperature.

The plastic extension at the beginning of the third stage was less than about 1 percent, except in specimens tested at relatively high strain rates or at a low temperature.
\end{abstract}

\section{Introduction}

The influence of strain rate and temperature on the mechanical properties of Monel and oxygenfree high-purity copper and the progress of fracture during creep of these metals were discussed in some detail in a previous paper [1]. ${ }^{1}$ The evidence presented indicated that the ductility of both metals increased with increase in strain rate and with decrease in temperature. The third stage of creep was sometimes initiated by the formation of microscopic cracks and with sufficiently slow strain rates at elevated temperature, specimens of both metals failed without local contraction. Since Monel and copper are facecentered cubic metals, the program on creep testing was extended to include a study of the behavior of body-centered cubic iron as affected by variations in strain rate and in temperature, and the results are given in the present paper.

Jenkins and Mellor [2] determined some properties of ingot and other commercial iron in tension tests made in vacuum at elevated temperatures and with different strain rates. In shorttime tests of ingot iron, initially as hot-rolled or normalized, the reduction of area increased from 73 percent at room temperature to 78 percent at $550^{\circ} \mathrm{C}$ and then decreased with further increase

\footnotetext{
1 Figures in brackets indicate the literature references at the end of this paper.
}

in temperature; the reduction of area at $350^{\circ} \mathrm{C}$ was less than at room temperature. At $350^{\circ} \mathrm{C}$, the reduction of area in a long time test $(46 \mathrm{hrs})$ was greater than in a short time test ( 75 and $64 \%$, respectively), whereas at all the higher temperatures used the reduction of area of the ingot iron was lower in creep than in the short time test. However, the creep tests were of relatively short duration and the strain rates in the second stage were not given. Tapsell and Clenshaw [3] made a study of the high-temperature properties of normalized ingot iron. Creep tests were made with different strain rates at temperatures ranging from about $450^{\circ}$ to $900^{\circ} \mathrm{F}$ for periods ranging from 2 to 70 days. The investigation with this iron was extended by Tapsell [4] to include creep tests at lower temperatures, Brinell hardness measurements at room temperature, and stressstrain curves at elevated temperatures of some of the specimens previously extended in creep, but the ductility of these specimens was not given.

\section{Material and Procedures Used}

The chemical composition, ferrite grain size, tensile properties, and hardness at room temperature of the ingot iron used in the initial condition as cold-drawn, approximately 13-percent reduction (in area) are given in table 1.

The apparatus used for carrying out the creep tests was the same as that described in some detail 
TABLE 1. Chemical composition and mechanical properties of the ingot iron used

The iron was initially in the form of a 34 -in. round bar as cold-drawn approxi. mately 13 -percent reduction in area

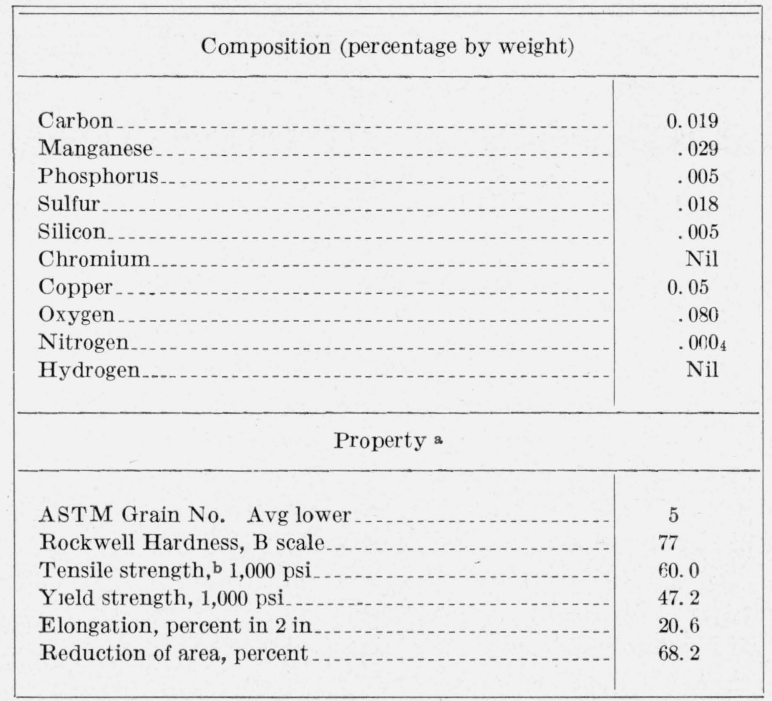

- As determined at room temperature.

b Drop of beam. by Bennett and McAdam [5]. All specimens used for creep testing were prepared from the same bar as cold-drawn, and these specimens were machined to American Society for Testing Materials Standard for $0.505 \mathrm{in}$. diameter with 2 to $4 \mathrm{in}$. gage lengths. Each specimen used for determining creep was heated in air (furnace atmosphere not controlled) to the desired temperature and held for $48 \mathrm{hr}$ before loading. The load was applied in selected increments in order to produce an approximate rate of extension of 30 to 50 percent per $1,000 \mathrm{hr}$ until the desired ultimate load for testing was attained; in one test the specimen was intentionally loaded at a relatively slow rate of 3 -percent extension in $1,000 \mathrm{hr}$. Thereafter the load was not changed on any specimen until the test was either completed or the third stage was reached. For specimens tested to fracture, the rate in the third stage was maintained approximately constant and equal to that in the second stage by repeatedly decreasing or adjusting the load. This procedure of maintaining a constant

TABLE 2. Summary of conditions used and results of creep tests on ingot iron initially as cold-drawn, 13-percent reduction in area

\begin{tabular}{|c|c|c|c|c|c|c|c|c|c|c|c|c|c|}
\hline \multirow{2}{*}{$\begin{array}{l}\text { Tem- } \\
\text { pera- } \\
\text { ture }\end{array}$} & \multirow{2}{*}{$\begin{array}{l}\text { Strain } \\
\text { rate a }\end{array}$} & \multirow{2}{*}{$\begin{array}{l}\text { Ulti- } \\
\text { mate } \\
\text { stress }\end{array}$} & \multicolumn{3}{|c|}{ Beginning of third stage } & \multicolumn{7}{|c|}{ End of test } & \multirow[b]{2}{*}{ Remarks } \\
\hline & & & Time & $\begin{array}{l}\text { Plastic } \\
\text { exten- } \\
\text { sion }\end{array}$ & $\begin{array}{l}\text { True } \\
\text { stress }\end{array}$ & Time & $\begin{array}{l}\text { Plastic } \\
\text { exten- } \\
\text { sion }\end{array}$ & $\begin{array}{l}\text { Reduc- } \\
\text { tion of } \\
\text { area }\end{array}$ & $L / L_{0}$ & $A_{0} / A$ & $\begin{array}{l}\text { True } \\
\text { stress }\end{array}$ & $\begin{array}{l}\text { Hard- } \\
\text { ness, } \\
\text { Rock- } \\
\text { well Bb }\end{array}$ & \\
\hline$\circ F$ & $\begin{array}{c}\% / 1,000 \\
h r\end{array}$ & $\underset{\text { in.2 }}{1,000 \mathrm{lb} /}$ & $h r$ & $\%$ & $\begin{array}{l}1,000 \mathrm{lb} / \\
\text { in } .^{2}\end{array}$ & $h r$ & $\begin{array}{l}\% \text { in } 2 \\
\text { in. }\end{array}$ & $\%$ & & & $\underset{\text { in.2 }}{1,000 l b /}$ & & \\
\hline 70 & $7 \times 10^{4}$ & 60.0 & 0.72 & 8.8 & 65.2 & 1.2 & 20.3 & 68.9 & 1. 20 & 3.21 & 120.0 & 77 & $\begin{array}{l}\text { Test made at room temperature on } \\
\text { specimens as cold-drawn. }\end{array}$ \\
\hline 70 & $6 \times 10^{4}$ & 60.0 & .51 & 7.0 & 65.3 & 1.1 & 21.0 & 67.5 & 1. 21 & 3.08 & 117.5 & 77 & Do. \\
\hline Avg & -......... & -......... & - n & 7.9 & 65.3 & 1. 2 & 20.6 & 68.2 & 1. 20 & 3.15 & 118.7 & 77 & \\
\hline 500 & 14.5 & 42.8 & 238 & 3.8 & 44.5 & 2,588 & • 37.3 & 50.5 & 1.37 & 2.0 & 70.6 & 69 & $\begin{array}{l}\text { Test stopped as load dropped sharp- } \\
\text { ly, indicating the start of fracture. }\end{array}$ \\
\hline 600 & 0.45 & 30.0 & 862 & 0.65 & 30.2 & 1,249 & 1.0 & 0.91 & 1.01 & 1.01 & 30.3 & 66 & $\begin{array}{l}\text { Test stopped after beginning of third } \\
\text { stage. }\end{array}$ \\
\hline 600 & 1.60 & 33.3 & 295 & .72 & 33.6 & 9,556 & c 16.5 & 56.6 & 1.17 & 2. 30 & 49.6 & 65 & Tested to fracture. \\
\hline 600 & 380 & 37.1 & 5.6 & 1. 73 & 37.9 & 130 & 50.0 & 76.7 & 1.50 & 4. 30 & 80.8 & 65 & Do. \\
\hline 600 & 1,340 & 39.5 & 5.0 & 5. 60 & 41.9 & 46.8 & 65.1 & 82.5 & 1.65 & 5. 72 & 102.4 & 65 & Do. \\
\hline 700 & 0.06 & 20.7 & 6,500 & 0.63 & 20.8 & 7,727 & с 0.72 & 0.08 & 1.01 & 1.00 & 20.7 & 60 & $\begin{array}{l}\text { Test stopped after beginning of third } \\
\text { stage. }\end{array}$ \\
\hline 700 & .39 & 22.5 & 863 & .62 & 22.7 & 3,350 & c 1.70 & 1. 29 & 1.02 & 1.013 & 22.1 & 60 & Do. \\
\hline 700 & 2.63 & 24.4 & 171 & .65 & 24.6 & 5,802 & c 16.4 & 44.7 & 1.16 & 1.81 & 30.2 & 62 & Tested to fracture. \\
\hline d 700 & 3.0 & 28.5 & 315 & .87 & 28.7 & 3,676 & c 11.2 & 45.4 & 1.11 & 1.83 & 39.0 & 62 & Tested to fracture; loaded slowly. \\
\hline 700 & 46.0 & 28.5 & 9.4 & .66 & 28.7 & 590 & 28.8 & 45.6 & 1.29 & 1.84 & 36.0 & 63 & Tested to fracture. \\
\hline 800 & 5.1 & 18.8 & 108 & .71 & 18.9 & 168 & 1.1 & 2.0 & 1.01 & 1.02 & 19. 2 & 56 & $\begin{array}{l}\text { Test stopped after beginning of third } \\
\text { stage. }\end{array}$ \\
\hline 800 & 17.0 & 20.5 & 41 & .80 & 20.7 & 53.8 & 1.2 & 1.0 & 1.01 & 1.01 & 20.7 & 56 & Do. \\
\hline 800 & 42.0 & 23.6 & 8 & .50 & 23.7 & 225 & с 9.2 & 42.3 & 1.09 & 1. 72 & 30.9 & 54 & Tested to fracture. \\
\hline
\end{tabular}

a Except for the tension tests made at $70^{\circ} \mathrm{F}$ (room temperature), the strain rate is the average value obtained during the second stage. The strain rate during the third stage of specimens tested to fracture was maintained nearly constant and equal to that in the second stage by repeatedly decreasing the load during the third stage. The specimens tested at elevated temperatures were loaded at a rate of 30 - to 50 -percent extension in $1,000 \mathrm{hr}$ in the first stage. b Hardness measurements were made on the undeformed (shoulder) of the specimens after testing in tension.

- Plastic extension, percent in 4 in.

d The specimen was loaded at a rate of 3 -percent extension in $1,000 \mathrm{hr}$ in the first stage. 
rate beyond the beginning of the third stage was considered essential in this study for, as pointed by McAdam and coworkers [1], when a creep test is made under a constant load the increasing rate in the third stage tends to cause an increase in ductility at fracture. The conditions used in making the creep tests are given in table 2 . Tests were made at $600^{\circ}, 700^{\circ}$, and $800^{\circ} \mathrm{F}$ with different strain rates and, in addition, a specimen was tested at $500^{\circ} \mathrm{F}$. In some cases, the test was discontinued after the beginning of the third stage of creep, whereas with other specimens the loads were adjusted and maintained until fracture occurred.

Rockwell B hardness (100-Kg load, 1/16-in. diameter ball) measu rements were made on the cross section of the bar initially as cold-drawn and on selected specimens after testing in creep. The amount of plastic deformation of each specimen fractured in creep varied over the "necked" section (local contraction). Two flats $180^{\circ}$ apart were prepared parallel to the longitudinal axis of the specimens after fracturing, and Rockwell readings were made at room temperature at various points along the center line of these flats. The diameters of the specimen at the points of indentation were accurately determined by means of a measuring microscope. As the shoulder of the tensile specimen (fig. 7) was not deformed during creep but was exposed to the same temperature for the same time as the plastically deformed section, the hardness value obtained on the shoulder was used as the basis for determining the change in hardness due to plastic deformation and the accompanying strain hardening, aging, and recovery during the creep tests.

In the tension tests made at room temperature, the specimens were extended at a rate of about 6 to $7 \times 10^{4}$ percent per $1,000 \mathrm{hr}$ to the maximum load, after which the load was gradually reduced so as to produce a nearly constant rate of reduction in area during the remainder of the test. The change in diameters of the specimens during the course of the test was followed with a micrometer. Usual procedures were followed in preparing specimens and carrying out the microscopic examination.

\section{Results and Discussion}

The results obtained in the creep tests are summarized in table 2 and figures 1 to 13 .
Representative extension-time curves for some of the specimens tested either to the beginning of the third stage or to complete fracture are reproduced in figures 1 and 2, respectively. As is illustrated by the shape of curves A and B in figure 1, the change in extension with time in the second stage frequently did not occur uniformly but varied in a cyclic manner. During the time of a cycle, the change in extension ranges from relatively high to low or negative values. That is, a period of acceleration in high strain rate was followed by negative creep (contraction of specimen) anc vice versa. The frequency and amplitude of these cycles apparently depended upon the temperature, strain rate, and the time elapsed in the second stage of creep. The trend was for both the frequency and amplitude of the cycles to decrease with an increase in either temperature (curves $\mathrm{A}$ and $\mathrm{B}$ ) or strain rate (curves B and C) and also to decrease as the deformation or time approached the beginning of the third stage of creep. It is believed that the cycles result from a combination of strain hardening, strain aging, and recovery (annealing) of the ingot iron. At sufficiently high strain rates and temperatures, strain aging was not manifested in the shape of the extensiontime curve, and the creep rate was nearly constant in the second stage (curve C). Because of the described behavior of some of the test specimens, the average and not the minimum values for creep during the second stage are given in table 2 and the several figures in this report; obviously, in some tests, the miminum creep rate actually was a negative value, and in other tests it corresponded to the average rate.

The time required to complete the third stage of creep under a controlled condition of constant rate was often considerably greater than the total time elapsed during the first and second stages (fig. 2). As is shown by the positions of the points as plotted in figure 2 , the rate during the entire third stage could be maintained at a desired and nearly constant value by the procedure of adjusting the load on the specimen; usually the rate increased somewhat just prior to complete fracture of the specimen due to a "rim" effect [1].

The relation between true stress ${ }^{2}$ and creep rate in the second stage of tests made at different temperatures is shown in figure 3 . With the se-

\footnotetext{
${ }^{2}$ The "true stress" is that value obtained by dividing the current load by the current minimum area of the specimen.
} 
lected rate of loading (30- to 50-\% extension per $1,000 \mathrm{hr}$ in the first stage of creep), the experimental values obtained at test temperatures of $600^{\circ}, 700^{\circ}$ and $800^{\circ} \mathrm{F}$ do not fall on a straight line when plotted on logarithmic coordinates. The trend was for the curves drawn through the experimental values to deviate from liniarity by bending downward with the slower, and upward with the higher ranges in strain rates used at each temperature; the tests at $800^{\circ} \mathrm{F}$ were not extended to relatively slow rates, but it would be expected that the results of such tests would also follow the downward path. Although the stress-strain rate curves follow the same general pattern, it is noteworthy that the curves are not parallel, and the relative positions where the bends occurred were influenced by the temperature of testing. Thus, the pronounced downward curvature was shifted to a lower creep rate as the temperature was changed from $600^{\circ}$ to $700^{\circ} \mathrm{F}$ and the upward curvature to higher rates as the temperature decreased. Similar trends are shown in the curves obtained when the experimental values for true stress are plotted against the logarithm of the strain rate. The shape of the stress-strain rate curve was not established at $500^{\circ} \mathrm{F}$ as only one creep test was made at this temperature. $500^{\circ} \mathrm{F}$ is within the so-called "blue heat" region where the effects of strain aging attain a maximum, as shown by the results of short-time tensile tests. It is to be expected, however, that this region would shift to a different range in temperature as the amounts of prior cold-working and creep rates are changed. According to Greaves and Jones [6], a maximum in the tensile strength-temperature curve of ingot iron occurred at about $300^{\circ} \mathrm{F}$ with relatively slow loading and at $700^{\circ} \mathrm{F}$ with fast loading. The relatively high ductility of the specimen tested at $500^{\circ} \mathrm{F}$ (fig. 6 and table 2) indicates that the conditions were such as to be above the blue heat range.

The use of a linear relationship in either a log-log or semi-log plot of true stress versus strain rate is not justified for extrapolating for very long service life of the initially cold-worked ingot iron at $600^{\circ}$ or $700^{\circ} \mathrm{F}$. Such an extrapolation would result in premature failure.

The resistance to creep at $700^{\circ} \mathrm{F}$ was materially increased by decreasing the rate of extension in the first stage during loading from about 40 to 3 percent per $1,000 \mathrm{hr}$; the plastic extension of fracture was also affected by variation in rate of loading (fig. 6). In previous investigations but little attention has been given to controlling the rate of extension during the first stage of creep, and this is a factor that merits further study. The results obtained with the two specimens loaded at different rates again serve to emphasize the importance of accurately controlling the conditions encountered in creep testing.

The effect of temperature on the resistance to creep of ingot iron is shown by a comparison of the positions of the stress-strain rate curves (fig. 3) and by the derived stress-temperature curves for creep rates of $1,5,10$, and 50 percent per 1,000 $\mathrm{hr}$, as given in figure 4 . With the semi-log plot used (fig. 4), the curves were not exactly linear, and their slopes varied somewhat with strain rates; the trend was for the family of curves of figure 4 to diverge as the temperature was increased. Obviously, the resistance to creep, that is, the stress required to produce a selected creep rate, increased as the temperature decreased.

As is illustrated in figure 5, the true fracture stress increased with an increase in strain rate (temperature constant) and with a decrease in test temperature (strain rate constant).

The influence of strain rate on the ductility of specimens tested in creep at different temperatures is shown in figure 6. Variations within the range of strain rates used had no significant effect on the plastic extension at the beginning of the third stage of creep of the specimens tested either at $700^{\circ}$ or $800^{\circ} \mathrm{F}$. Furthermore, the extension at the beginning of the third stage of specimens tested at $600^{\circ} \mathrm{F}$ with strain rates less than about 2 percent per $1,000 \mathrm{hr}$ was about the same as that obtained in the tests at $700^{\circ}$ and at $800^{\circ} \mathrm{F}$; the extension of each of these specimens was less than 1 percent. However, the extension at the beginning of the third stage of creep was materially increased in specimens tested at $600^{\circ} \mathrm{F}$ by increasing the strain rate to relatively high values and also in another specimen tested at a lower temperature $\left(500^{\circ} \mathrm{F}\right)$ with a strain rate of only about 15 percent per $1,000 \mathrm{hr}$. The result of this latter test supports the belief that the relation between strain rate and plastic extension at the beginning of the third stage of creep of specimens tested at $500^{\circ}, 700^{\circ}$, and $800^{\circ} \mathrm{F}$ is represented by a family of curves similar in shape to that obtained at $600^{\circ} \mathrm{F}$; the start of the bend in these curves is 
displaced to a lower strain-rate value at $500^{\circ} \mathrm{F}$, and to higher values at $700^{\circ}$ and $800^{\circ} \mathrm{F}$, than that at $600^{\circ} \mathrm{F}$. That is, the point of divergence in the curve is shifted to a lower creep rate as the temperature of the test is decreased, and at $500^{\circ} \mathrm{F}$ a strain rate of 15 percent per $1,000 \mathrm{hr}$ is considerably above this point.

At $600^{\circ} \mathrm{F}$, the ductility at fracture, as determined both by plastic extension and reduction of area, decreased with a decrease in strain rate. At $700^{\circ} \mathrm{F}$, the extension also decreased with a decrease in strain rate, whereas the reduction of area was not appreciably affected by this change. At $800^{\circ} \mathrm{F}$, the plastic extension at fracture of a specimen tested at a strain rate of about 45 percent per $1,000 \mathrm{hr}$ was considerably less than that of a specimen tested at $700^{\circ} \mathrm{F}$ at the same rate, but values for the reduction of area of the two specimens at fracture were nearly alike.

For a selected strain rate, the plastic extension at fracture decreased continuously as the temperature of the creep test increased, but no consistent relationship was obtained between temperature and the reduction of area. It is to be expected that the temperature might affect differently the ductility as determined by extension and reduction of area, as the stress during the third stage of creep was not unidirectional. Although the strain rate was controlled and maintained nearly constant in this stage, considerable necking occurred in each specimen tested to fracture. In some cases, the necking was confined principally to a relatively narrow region in the vicinity of the fracture (fig. 7, B), whereas in other specimens there was a more gradual necking over a considerable portion of the gage length (fig. 7, A). Both the extension and reduction of area were affected by the manner in which the specimen necked, but not necessarily to the same degree.

Since the described trends for the ductility to increase with an increase in strain rate and with a decrease in temperature were shown in the creep tests, it is of particular interest to compare some of the values for ductility at $600^{\circ} \mathrm{F}$ (fig. 6) with that obtained at room temperature in ordinary tension tests (table 2). Although the latter tests were made at a considerably faster rate and lower temperature than the former (both factors tend to cause an increase in ductility in creep), the values for plastic extension and reduction of area at fracture in the room-temperature tests were significantly lower than the maximum attained at $600^{\circ} \mathrm{F}$. The combined effects of strain rate, aging, and temperature on the ductility of ingot iron vary appreciably depending on the testing conditions. Evidently the strain ratetemperature and temperature-ductility curves for this material would show a reversal in curvature when the testing conditions are changed from the high strain rates used in creep at elevated temperature to considerably higher strain rates obtained in the tension test at atmospheric temperatures; the reversals may even occur in the low-temnerature range used in the creep tests.

The relation of fracture stress to ductility in creep is shown in figure 8 . At $600^{\circ} \mathrm{F}$, the fracture stress increased continuously with an increase in both plastic extension and reduction of area. This trend for the fracture stress to increase with plastic extension was also obtained in two specimens tested at $700^{\circ} \mathrm{F}$ (loaded at the same rate), but there was a considerable difference in the stress at fracture of these specimens, although both had approximately the same reduction of area. This latter condition is also attributed to a difference in the manner of necking of the two specimens, as is illustrated by typical photographs given in figure 7 . The fracture stress at $700^{\circ} \mathrm{F}$ of the specimen loaded relatively slowly in the first stage was somewhat higher than that of the specimens loaded at the higher rate; the plastic extension of the former specimen was also lower, but the reduction of area was approximately the same for each specimen. At $800^{\circ} \mathrm{F}$, the fracture stress was less than that at $700^{\circ} \mathrm{F}$ when the specimens were tested at the same strain rate of about 45 percent per $1,000 \mathrm{hr}$, but it was of the same order of magnitude of that of a specimen tested at $700^{\circ} \mathrm{F}$ with a slower strain rate $(2.6 \%$ per $1,000 \mathrm{hr})$.

As previously pointed out, the final ductility of a specimen of ingot iron tested in creep is affected by the strain rate and the tempezature at which the test is made. Both of these factors also influence the stress necessary to cause fracture.

The influence of temperature on the resistance to plastic deformation in the early stage of creep of ingot iron is shown by the relative positions of the curves reproduced in figure 9 . At $800^{\circ} \mathrm{F}$, plastic deformation commenced with the application of a relatively small stress, whereas at $500^{\circ}$ $\mathrm{F}$ the extension was elastic with stresses up to about $20,000 \mathrm{lb} / \mathrm{in}^{2}$. The relation of temperature 
TABLE 3. Tensile properties at room temperature of specimens of ingot iron after extending at different temperatures and strain rates into the beginning of the third stage of creep and of specimens as aged at different temperatures

All specimens were prepared from the same bar as initially cold-drawn, 13-percent reduction in area and were finally tested in tension at room temperature at an approximate strain rate of $7 \times 10^{4} \% / 1,000 \mathrm{hr}$

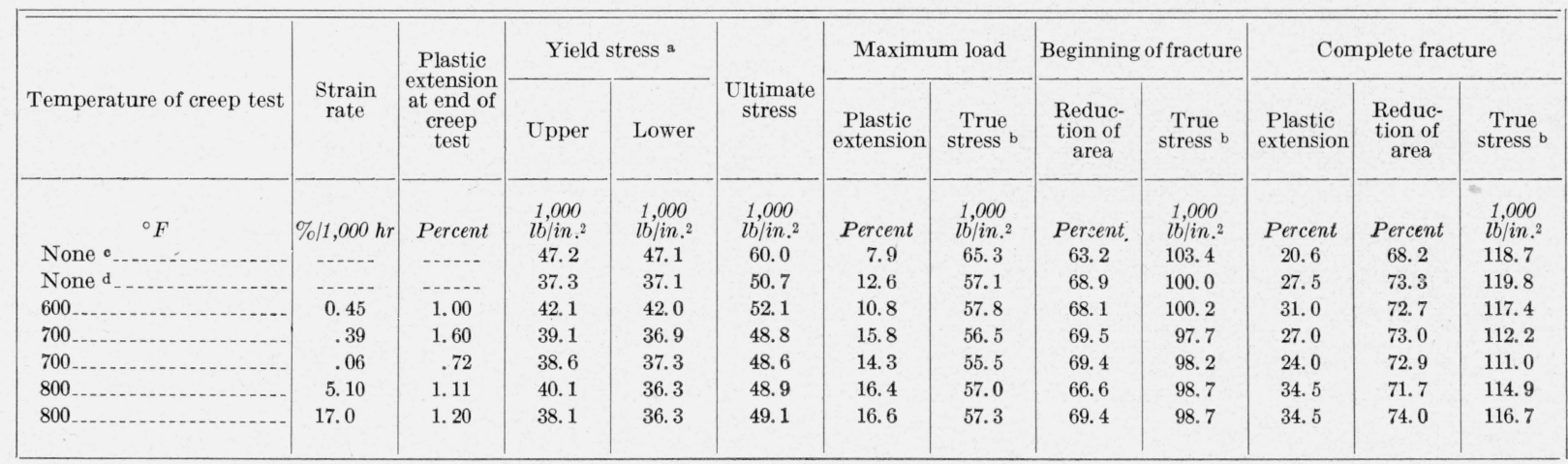

a Drop of beam.

b The true stress is that value obtained by dividing the current load by the current minimum area of the specimen.

- Tension tests made in duplicate on specimens aged at room temperature and not tested in creep.

d Tension test made on a specimen aged at $800^{\circ} \mathrm{F}$ for $48 \mathrm{hr}$ and not tested in creep.

to yield stress for 0.2 percent extension is given in figure 10. The yield strength decreases rapidly with increase in temperature used in the creep tests. However, the yield strength at $500^{\circ} \mathrm{F}$ was only slightly less than that obtained at room temperature in the ordinary tension test, which was also made at a considerably higher strain rate ( $40 \%$ and $7 \times 10^{4} \%$ per $1,000 \mathrm{hr}$, respectively). Tension tests were not made at temperatures between $70^{\circ}$ and $500^{\circ} \mathrm{F}$, and the exact location of the yield stress-temperature curve was not established through this temperature range. However, according to Carpenter and Robertson [7], the yield (point) strength, in general, should decrease as the temperature of testing is raised. The hardness at room temperature of the specimens as exposed at the temperatures for the time used in the creep tests also decreased with an increase in temperature, and these values were appreciably lower than that of the original cold-worked iron.

The specimens tested into the third stage of creep (not fractured) were unloaded and then cooled in the furnace to room temperature. A summary of the results of measurements made at room temperature for change in diameter over the entire gage length and the determination of extension during creep of these five specimens (one specimen tested at $600^{\circ}$, two at $700^{\circ}$, and two at $800^{\circ} \mathrm{F}$, table 2) showed no evidence of local contraction in four and only a very slight indication of necking in the other specimen $\left(800^{\circ}\right.$ $\mathrm{F}$ with strain rate of $5.1 \%$ per $1,000 \mathrm{hr}$ ). Actually, a comparison of the values for extension during creep $\left(L / L_{0}\right)^{3}$ with comparable values for the reduction of area obtained after cooling to room temperature $\left(A_{0} / A\right)$ indicate that there was a slight increase in volume of four of the specimens during creep. This is to be expected from cold-working, even when carried out under conditions where necking could not possibly occur. An oxide film formed on the specimens during exposure at test temperature, especially those at $800^{\circ} \mathrm{F}$, but the change in volume from the presence of this film was negligible. These specimens were then tested in tension at room temperature under controlled conditions, as previously described. Another specimen as cold-drawn was heated at $800^{\circ} \mathrm{F}$ (highest temperature used in the creep tests) for $48 \mathrm{hr}$ and then cooled to room temperature and tested in tension. The results of these tests are summarized in table 3 and figure 11.

The flow curves at room temperature for the two specimens previously extended at different rates to about 1 percent at $800^{\circ} \mathrm{F}$ are nearly alike, and the position of these curves was only slightly below that of the specimen aged only at $800^{\circ} \mathrm{F}$. As all the specimens tested in creep were aged for this same period $(48 \mathrm{hr}$ ) before loading, the small differences obtained in the stresses required to produce flow is believed to be due to the additional aging or recovery of the creep specimens during

${ }^{3} L_{0}$ and $A_{0}$ are the initial gage length and area of cross section, respectively; $L$ and $A$ are the current length and area, respectively. 
their longer exposure at $800^{\circ} \mathrm{F}$. The results of hardness tests made at room temperature on undeformed sections of these specimens indicate that some additional softening occurred when the aging time exceeded $48 \mathrm{hr}$. The flow curves at room temperatue for the two specimens extended in creep at $700^{\circ} \mathrm{F}$ (not shown in fig. 11) were quite similar to that of the curve reproduced for the specimens tested in creep at $800^{\circ} \mathrm{F}$; the former fall just below the latter curve. The resistance to flow at room temperature of the specimen extended at $600^{\circ} \mathrm{F}$ to the beginning of the third stage was somewhat greater than that of the specimens similarly extended at higher temperatures $\left(700^{\circ}\right.$ and $800^{\circ} \mathrm{F}$ ). As is to be expected, the resistance to flow of all the specimens aged at elevated temperatures was lower than that of the specimen aged at room temperature, but this decrease in flow stress was accompanied by a corresponding increase in ductility. The significant feature brought out by the tension tests at room temperature is that no appreciable deterioration in these mechanical properties of initially cold-drawn ingot iron resulted from its extension into the beginning of the third stage of creep (about $1 \%$ extension at $600^{\circ}, 700^{\circ}$, or $800^{\circ} \mathrm{F}$.

No cracks were visible on the surface of any of these specimens as extended into the third stage of creep. Furthermore, no indication of cracking was observed in a metallographic examination at magnifications of 500 to 1,000 diameters in the necked section extending from the axis to the surface of another specimen tested at $500^{\circ} \mathrm{F}$ to nearly the end of the third stage; that is, this particular creep test was carried out to the point where the load required to maintain a constant creep rate dropped sharply, and complete fracture would have occurred in a few minutes had the test continued without changing the load.

Determinations made on the specimens fractured in creep also supports the view that the third stage of creep was initiated in each specimen without the occurrence of necking. However, regardless of the rate of extension, some necking occurred during the third stage of creep in each specimen tested to complete fracture.

Some of the structural features of the ingot iron before and after testing in creep are illustrated by the typical photomicrographs reproduced in figure 12. The average size of the ferrite grains in the initially cold-drawn bar corresponds to the lower range of American Society for Testing Materials grain number 5 (fig. 12, A). These grains were elongated only slightly in the direction of coldworking, and the inclusions were frequently alined in streaks parallel to the direction of hot- and cold-working Some of these inclusions were fractured during the hot- and cold-working, but apparently no further change occurred in either their form or distribution during creep. Although the ingot iron contained the usual numerous oxides, these inclusions had no appreciable effect on the type of fracture produced in creep.

The fracture of the specimen tests at $600^{\circ} \mathrm{F}$ with a strain rate of 1.6 percent per $1,000 \mathrm{hr}$ (fig. 12, B) was essentially transcrystalline, whereas the fractures of specimens tested with higher strain rates (380 and 1,340 percent per $1,000 \mathrm{hr}$ ) were partially intercrystalline but predominantly transcrystalline (fig. 12, C). The fractures of all specimens at $700^{\circ}$ and $800^{\circ} \mathrm{F}$ were predominantly intercrystalline (fig. 12, D, E, and F).

The general tendency for the ferrite grains to elongate in the vicinity of complete fracture and to separate at points other than at complete fracture is also shown by a comparison of these photomicrographs. The maximum distortion of the grains during creep was obtained in a specimen tested at $600^{\circ} \mathrm{F}$ with a relatively high strain rate (fig. 12, C), and cracking was observed only in the region of complete separation; this specimen had a pronounced neck and relatively high ductility. Appreciable elongation of the grains also occurred in another specimen tested at $600^{\circ} \mathrm{F}$ with a creep rate of 1.6 percent per $1,000 \mathrm{hrs}$ (fig. 12, B), but there was some separation of the grains in regions away from the position of complete fracture. The general trend was for the flow to increase with a decrease in test temperature and to increase with an increase in strain rate. The tendency for the ferrite grain to separate in the regions away from the position of complete fracture was promoted by decreasing the strain rate and by increasing the temperature. No appreciable difference was detected in the structure of the specimens near the center and surface in the vicinity of the fractures. Where minor differences were observed, possibly somewhat greater amounts of flow occurred at the surface than in the center.

The effect of plastic deformation during creep at different temperatures on change in hardness 
at room temperature is shown by the results given in figure 13. The change in hardness as determined at room temperature was affected by the degree of plastic deformation, strain rate, temperature of the creep test, and rate of loading. For example, in a test made at $700^{\circ} \mathrm{F}$ with a strain rate of 2.63 percent per $1,000 \mathrm{hr}$, no change in hardness was observed with increase in plastic deformation up to 20-percent reduction in area, whereas in another test at $700^{\circ} \mathrm{F}$, with a strain rate of 46 percent per $1,000 \mathrm{hr}$; the hardness increased as the specimen was deformed to this same degree. With further plastic deformation the propensity of each of these two specimens to strain harden (and age) was less than in their response to recovery (anneal), and both showed relatively rapid decrease in hardness as the deformation increased. At temperatures of $500^{\circ}$ and $600^{\circ} \mathrm{F}$, the maximum increase in hardness with plastic deformation was greater than that obtained at the higher test temperatures, and the peak in the curve also occurred at greater amounts of plastic deformation. The general trends were for the amount of induced hardness to increase with an increase in strain rate and with a decrease in both test temperature and rate of loading and the recovery to increase with an increase both in temperature and plastic deformation; the exception to this trend was that in the tests at $700^{\circ}$ and $800^{\circ} \mathrm{F}$ with a strain rate of about 45 percent per $1,000 \mathrm{hr}$, slightly greater induced hardness was observed in the latter than in the former specimen.

The amount of uniform deformation in creep (extension to the beginning of necking) varied with the strain rate in that at a constant temperature $\left(600^{\circ}\right.$ and $700^{\circ} \mathrm{F}$, specimens loaded alike) the amount increased continuously as the strain rate increased. No consistent relationship, however, was shown between test temperature and the extent of uniform extension (constant strain rate).

A significant feature is the extent of this plastic deformation in creep before necking occurred. As already pointed out, the plastic extension at the beginning of the third stage was less than 1 percent in all specimens tested at slow strain rates, except one at $500^{\circ} \mathrm{F}$ with a strain rate of 14.5 percent per $1,000 \mathrm{hr}$; the extension at the start of the third stage was also greater than 1 percent in two specimens tested at $600^{\circ} \mathrm{F}$ with relatively high strain rates for testing in creep. Thus, in general, the initially cold-drawn specimens of ingot iron continued to extend uniformly in creep for an appreciable time after the start of the third stage.

It should be emphasized that the curves in figure 13 show the change in hardness at room temperature of specimens extended in creep at elevated temperatures, and the relative positions of these curves do not indicate the order or the actual hardness values of the test specimens during creep.

The hardness tests were extended to include specimens tested in tension at room temperature and aged at room or at elevated temperatures. A summary of these results (fig. 14) shows that there was a continuous increase in hardness with plastic deformation up to about 50-percent reduction in area; thereafter the hardness either remained constant or decreased as the distance from the point of fracture diminished. Although the general shape of the family of eurves is quite similar, the hardness induced by plastic deformation was increased appreciably by heating at $500^{\circ}$ or $800^{\circ} \mathrm{F}$. This increase in hardness is believed to be due to a state of more complete aging at elevated temperatures (overaged at $800^{\circ} \mathrm{F}$ in 48 $\mathrm{hr}$ ) of the cold-worked specimen.

These hardness tests were made solely to supplement the data obtained in the creep tests. Obviously, no definite correlation could be expected between hardness measurements made at room temperature and creep behavior at elevated temperatures. However, the hardness measurements give some indication of the aging characteristics of this particular lot of initially cold-drawn ingot iron and its resistance to plastic deformation occurring during creep, especially after the beginning of necking. The results confirm the already known fact that the history of the specimen is continuously changing during creep, and they show that changes in hardness of ingot iron similar to its creep properties are affected by variations in amounts of plastic deformations, strain rates, and temperatures.

\section{Summary}

Tension tests were made at different straiu rates and temperatures on ingot iron initially cold-drawn approximately 13 -percent reduction in area. Some of the creep tests at $600^{\circ}, 700^{\circ}$, and $800^{\circ} \mathrm{F}$ were discontinued after the beginning of the third stage, and these specimens were subse- 
quently tested in tension at room temperature. In another series of tests in which the specimens were carried to complete fracture at $500^{\circ}, 600^{\circ}$, $700^{\circ}$, and $800^{\circ} \mathrm{F}$, the strain rate during the third stage was maintained nearly constant and equal to that in the second stage by repeatedly adjusting the load during the third stage. Hardness measurements at room temperature and metallographic examination were made on specimens representative of the initial material and after testing in creep under the varying conditions used.

The relationship between true stress and the creep rate in the second stage was not linear when either the stress or the logarithm of the stress was plotted against the logarithm of the strain rate. The use of a linear relationship in either of these plots for extrapolating to very slow strain rates is not justified.

The resistance to creep in the second stage and the extension at complete fracture at $700^{\circ} \mathrm{F}$ were materially affected by variations in rate of loading in the first stage.

Although variations within the range of strain rates used in the creep tests at $700^{\circ}$ and $800^{\circ} \mathrm{F}$ had no significant effect on plastic extension at the beginning of the third stage, evidence obtained in tests at $500^{\circ}$ and $600^{\circ} \mathrm{F}$ supports the belief that this extension is markedly increased with sufficiently high strain rates. The strain rates required to produce relatively high plastic extension at the beginning of the third stage were affected by the test temperature in that the high ductility was obtained at slower rates as the test temperature was decreased.

The third stage of creep was initiated without necking of the specimens, and the results of tension tests made at room temperature on specimens previously extended into the third stage at different temperatures showed that no general deterioration or microcracking of the specimen occurred up to the time this stage was reached. Regardless of strain rate or temperature used, however, considerable necking occurred during the third stage of each specimen tested to complete fracture.

The general trend was for the ductility (plastic extension and reduction of area) at fracture to increase as the strain rate increased. The plastic extension at fracture decreased with an increase in test temperature, but in the creep test no consistent relation was obtained between temperature and reduction of area at fracture.

The resistance to both creep and fracture increased as the temperature was decreased. The stress at fracture also increased as the strain rate increased.

The fractures were predominantly transcrystalline in the tension tests with the different strain rates used at and below $600^{\circ} \mathrm{F}$ and intercrystalline at test temperatures of $700^{\circ}$ and $800^{\circ} \mathrm{F}$.

The authors are indebted to G. W. Geil for his assistance in planning the testing program and to Fannie A. Wilkinson for making many of the measurements during the course of the investigation.

\section{References}

[1] D. J. McAdam, Jr., G. W. Geil, and D. H. Woodard, Influence of strain rate and temperature on the mechanical properties of Monel metal and copper, Proc. Am. Soc. Test. Mat. 46, 902 (1946).

[2] C. H. M. Jenkins and G. A. Mellor, Investigation of the behavior of metals under deformation at high temperatures. Part I-Structural changes in mild steel and commercial irons during creep, J. Iron \& Steel Inst., 132, 179 (1935).

[3] H. J. Tapsell and W. J. Clenshaw, Mechanical properties of Armco iron, 0.17 percent carbon steel, and 0.24 percent carbon steel, with special reference to creep, Great Britain Department of Scientific and Industrial Research Engineering Research Special Report No. 1 (1927-29).

[4] H. J. Tapsell. Note on the "creep" of Armco iron, Great Britain Department of Scientific and Industrial Research, Engineering Research, Special Report No. 6 (1927-29); H. J. Tapsell, Creep of metals, (Oxford Univ. Press, 1931).

[5] J. A. Bennett and D. J. McAdam, Jr. Creep rates of cold-drawn nickel-copper alloy (Monel metal), J. Research NBS, 28, 417 (1942) RP1462.

[6] R. H. Greaves and J. A. Jones, The effect of temperature on the behavior of iron and steel in notched-bar impact tests, J. Iron \& Steel Inst. 112, 123 (1925).

[7] H. Carpenter and J. M. Robertson, Metals 1, 174 (Oxford Univ. Press, 1939). 


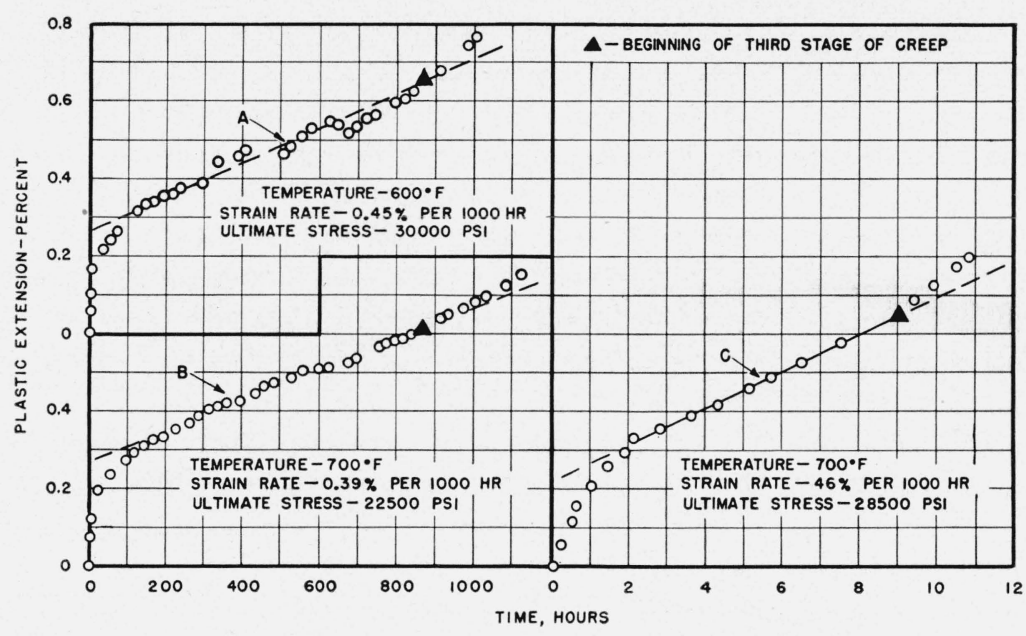

FIGURE 1. Extension-time curves for specimens extended into the third stage of creep.

FIGURE 2. Extension-time curves for specimen tested in creep to complete fracture.

The strain rate during the third stage was maintained nearly constant and equal to that of the second stage by repeatedly decreasing the load during the third stage.
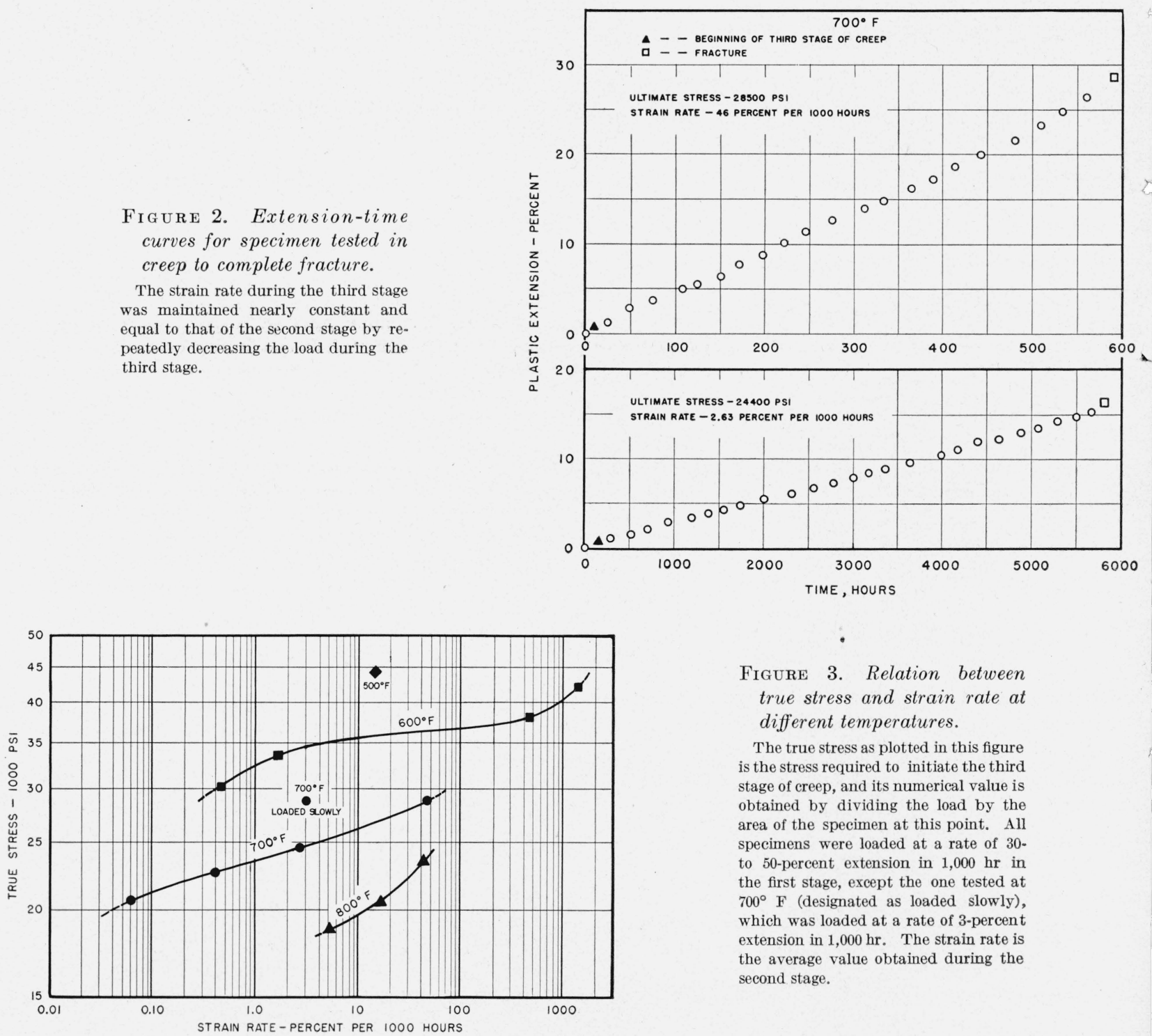


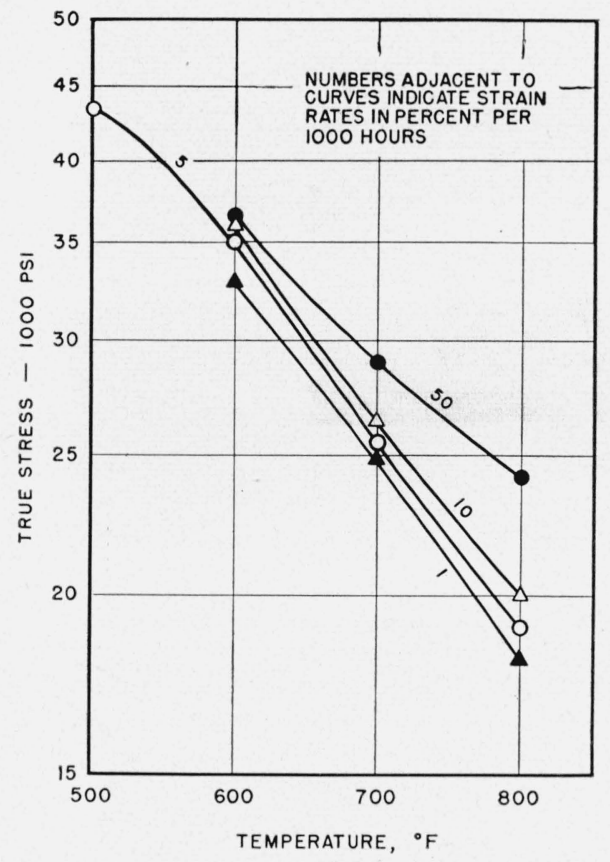

Figure 4. Relation between temperature and the stress required to produce different strain rates.

The values were derived from figure 3.

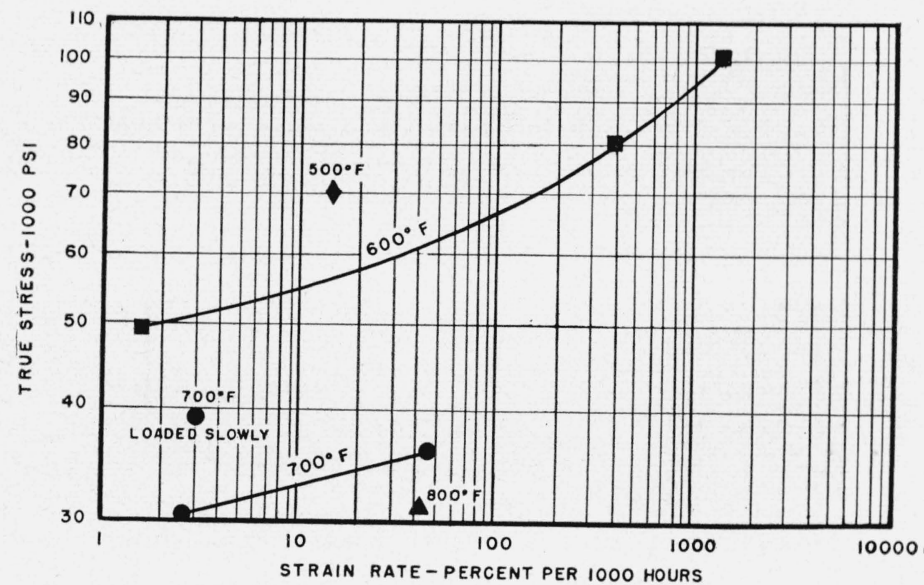

FIGURE 5. Relation between strain rate and true stress at fracture.

The true stress at fracture is obtained by dividing the load at the time of fracture by the area of the specimen at the point of fracture. The strain rate is the average rate obtained in the second stage of creep. The strain rate during the third stage was maintained nearly constant and equal to that of the second stage by repeatedly decreasing the load during the third stage.

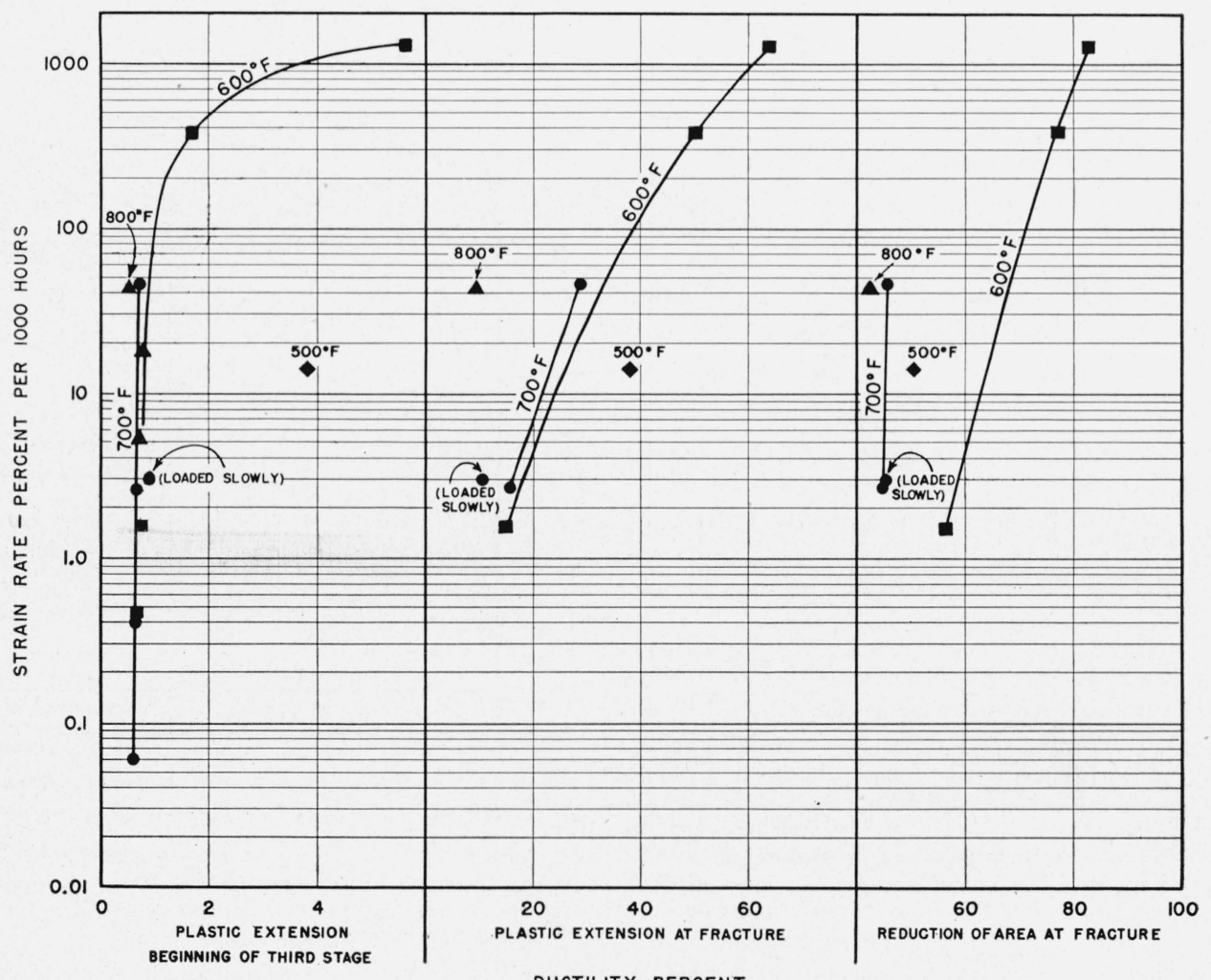

DUCTILITY-PERCENT

FIGURE 6. Influence of strain rate on ductility at different temperatures.

The strain rate is the average rate obtained during the second stage of creep. The strain rate during the third stage was maintained nearly constant and equal to that of the second stage by repeatedly decreasing the load during the third stage. 

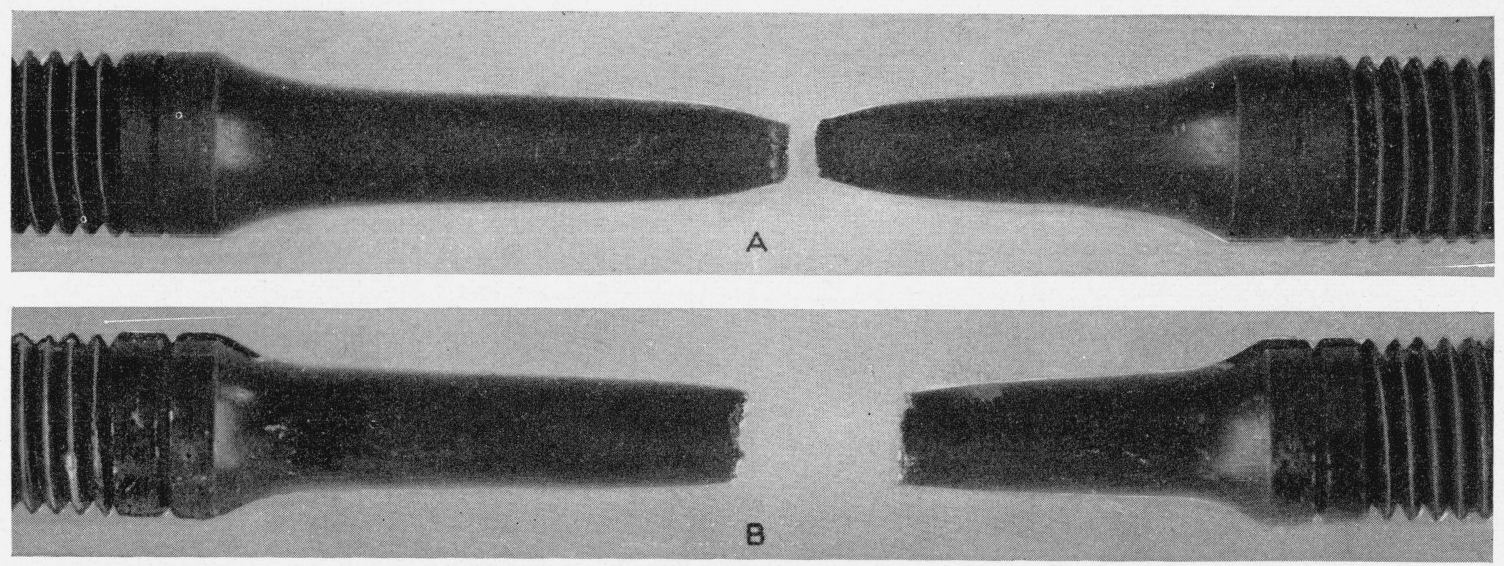

Figure 7. Photographs of specimens after fracturing in creep. $\times 1$.

A, Specimen tested at $600^{\circ} \mathrm{F}$ with a strain rate of 380 percent per $1,000 \mathrm{hr}$. Necking extended over a considerable portion of the gage length. $L / L_{0}=1.50 ; A_{0} / A=4.30$. B, Specimen tested at $700^{\circ} \mathrm{F}$ with a strain rate of 46 percent per $1,000 \mathrm{hr}$. Necking was confined principally to the region near the fracture. $L / L_{0}=1.29 ; A_{0} / A=1.84$. $L_{0}$ and $A_{0}$ are the initial gage length and area of cross section respectively; $L$ and $A$ are the length and area at fracture, respectively.

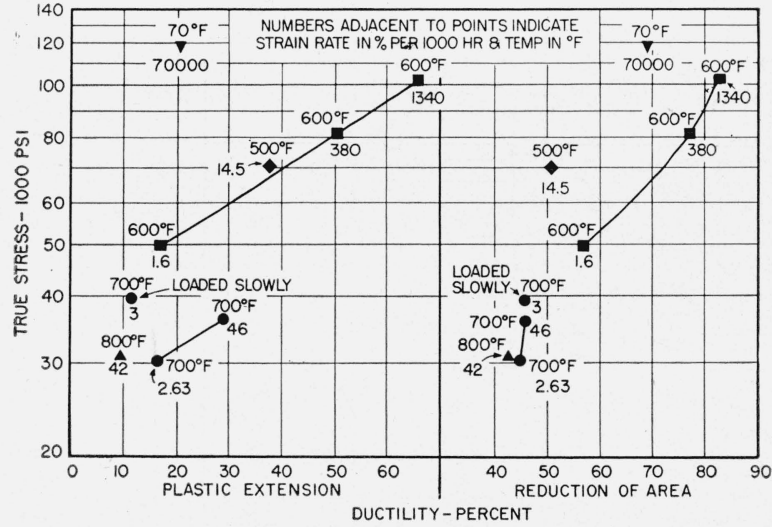

FIGURE 8. Relation between stress at fracture and ductility at different temperatures and strain rates.

The true stress at fracture is obtained by dividing the load at the time of fracture by the area of the specimen at the point of fracture. All specimens were loaded at a rate of 30 - to 50 -percent extension in $1,000 \mathrm{hr}$ in the first stage of creep, except one tested at $700^{\circ} \mathrm{F}$ (designated as loaded slowly), which was loaded at a rate of 3-percent extension in 1,000 hr. The strain rate in the third stage was maintained nearly constant and equal to that of the second stage (values given in fig.) by repeatedly decreasing the load during the third stage.

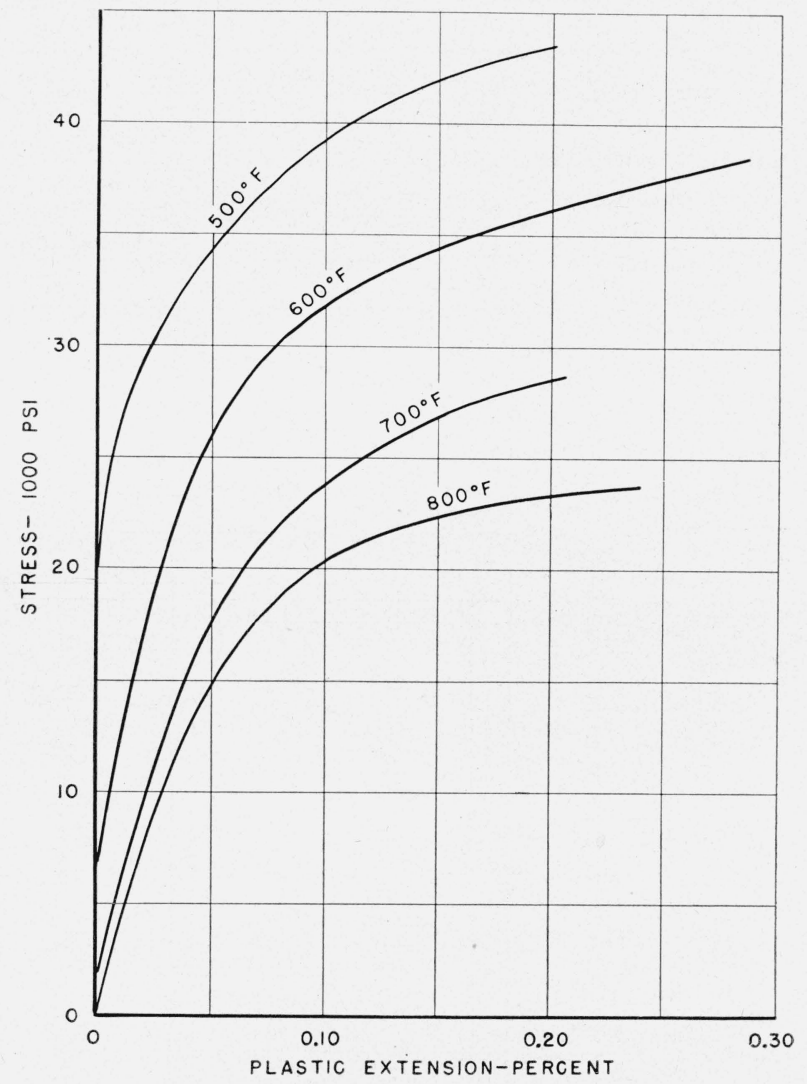

Figure 9. Effect of nominal stress on plastic extension in the initial stage of creep at different temperatures.

The specimens were prepared from the bar as cold-worked 13 percent and were loaded under conditions required to produce a rate of extension of 30 to 50 percent per $1,000 \mathrm{hr}$. The curves are drawn through the mean positions of numerous experimental points. 


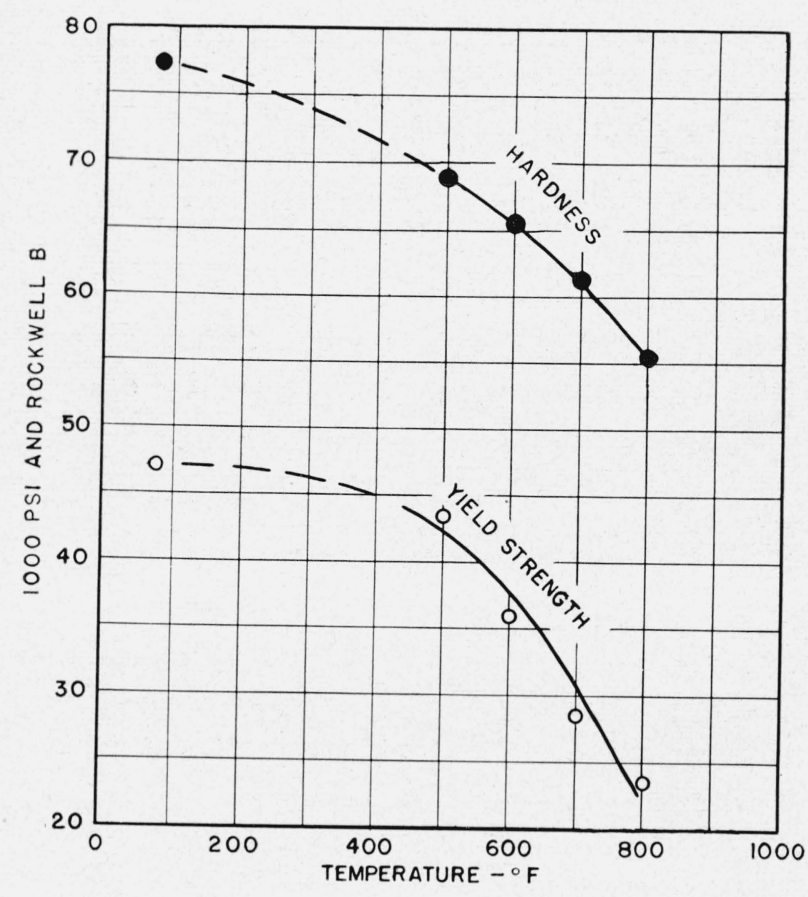

Figure 10. Effect of temperature on yield strength and Rockwell B Hardness.

Values for yield stress $(0.2 \%$ offset) at elevated temperatures were derived from figure 9. The Rockwell hardness tests were made at room temperature on the initially cold-worked bar and on the undeformed portion (shoulder) of the specimen after testing in creep at different temperatures.

Figure 11. Effect of extending in creep at different temperatures to the beginning of the third stage and of aging at $800^{\circ} \mathrm{F}$ on the tensile properties at room temperature of cold-drawn ingot iron.

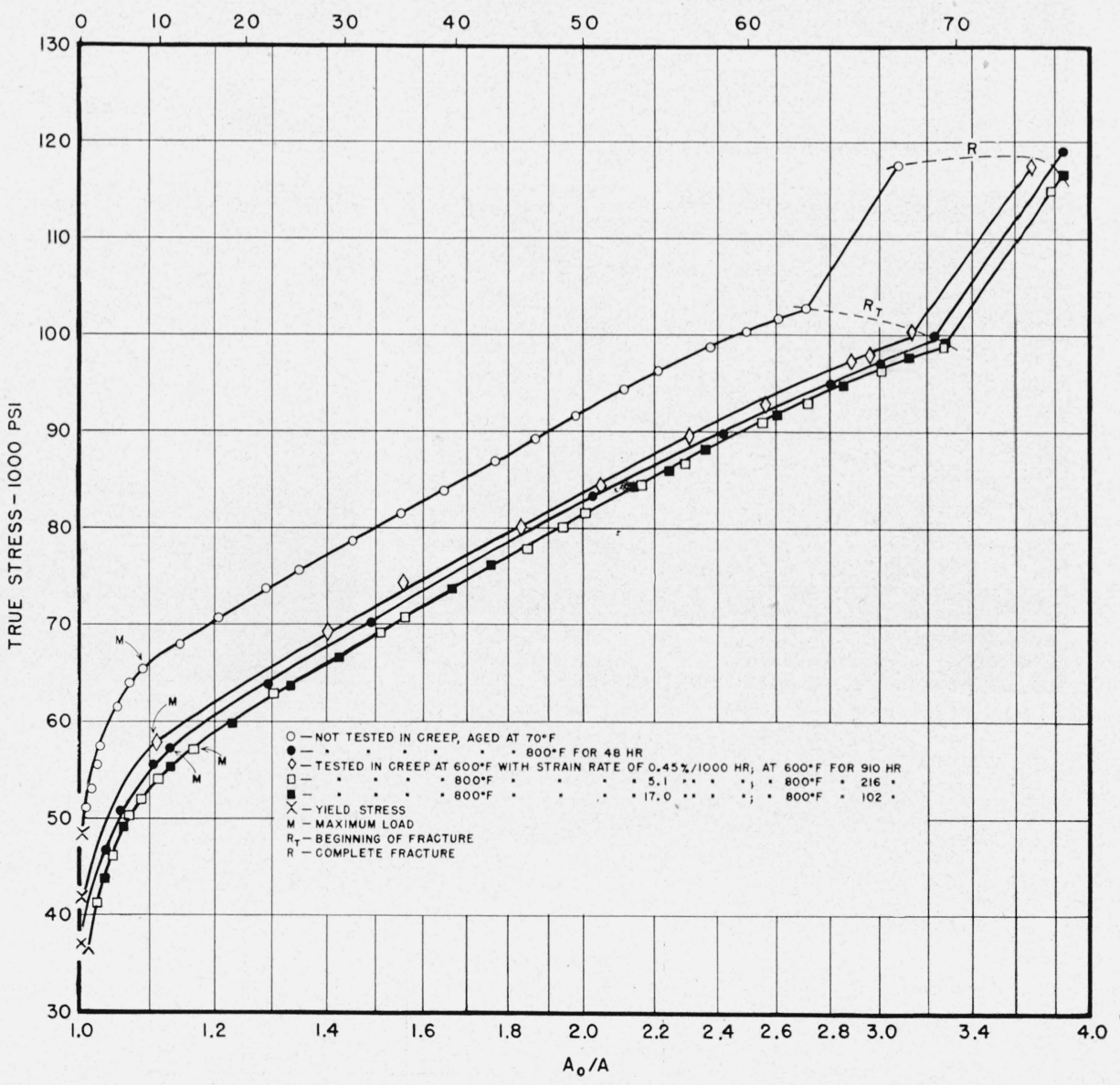



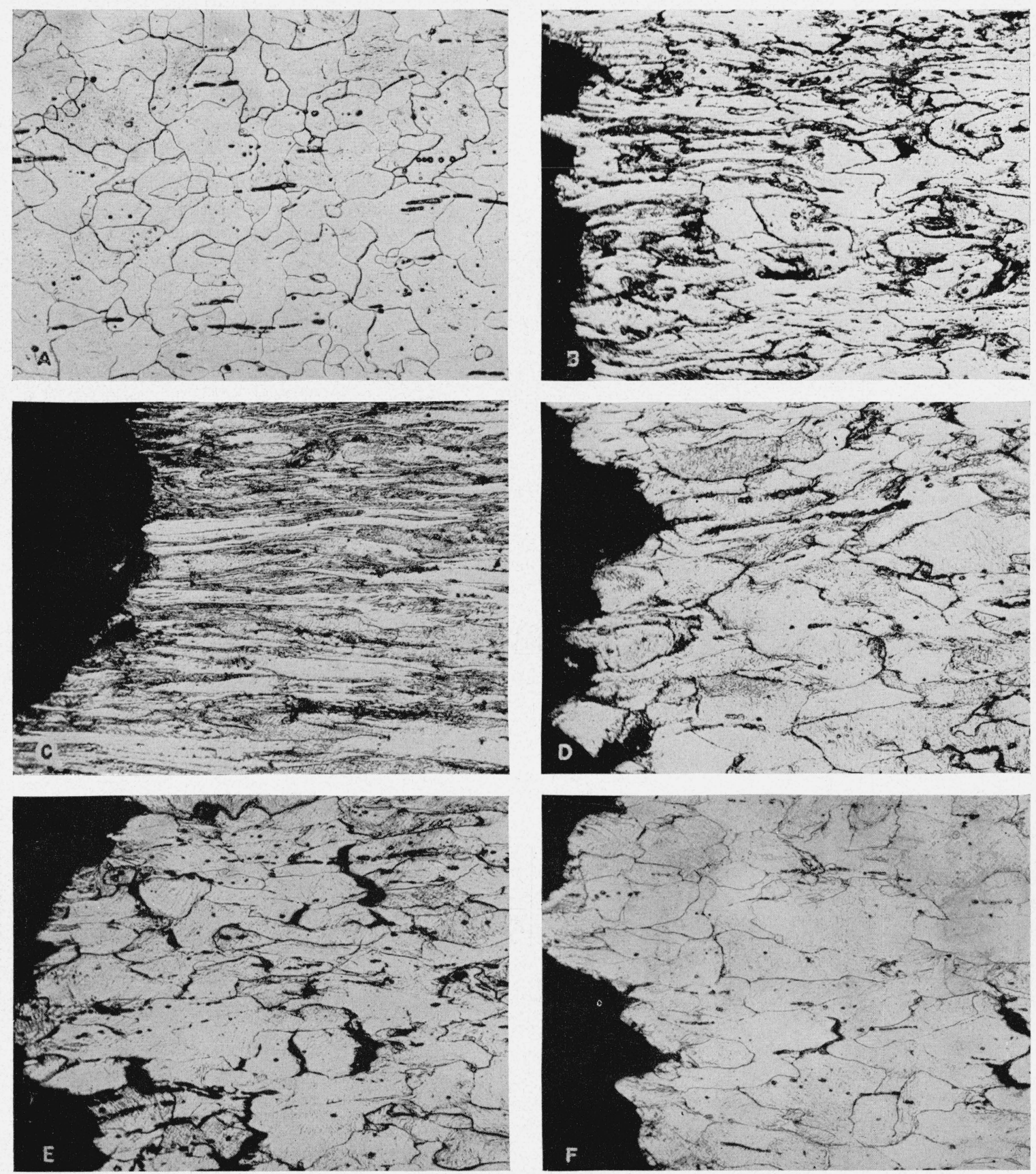

FIGURE 12. Ferrite grain size of cold-drawn ingot iron and typical structures at fracture of specimenstested in tension at different temperatures and strain rates; longitudinal sections, etched in nital, $\times 100$.

\begin{tabular}{|c|c|c|c|c|c|}
\hline \multirow{2}{*}{ Figure } & \multicolumn{2}{|l|}{ Test } & \multirow{2}{*}{$\begin{array}{l}\text { Elon- } \\
\text { gation } \\
\text { in } 4 \text { in. }\end{array}$} & \multirow{2}{*}{$\begin{array}{l}\text { Reduc- } \\
\text { tion in } \\
\text { area }\end{array}$} & \multirow{2}{*}{ Remarks } \\
\hline & Temperature & Strain rate & & & \\
\hline A. & ${ }^{\circ} \mathrm{F}$ & $\% / 1,000 \mathrm{hr}$ & $\%$ & $\%$ & $\begin{array}{l}\text { As cold-drawn; AVG } \\
\text { ASTM grain No. } \\
\text { lower } 5 \text {. }\end{array}$ \\
\hline B. & 600 & 1.60 & 16.5 & 56.6 & - \\
\hline C... & 600 & 1340 & a 65.1 & 82.5 & - \\
\hline D... & 700 & 2. 63 & 16.4 & 44.7 & \\
\hline $\mathrm{E}$ & 700 & 3.00 & 11.2 & 45.4 & Loaded slowly. \\
\hline F. & 800 & 42 & 9.2 & 42.3 & - \\
\hline
\end{tabular}

\footnotetext{
a Elongation in 2 in., percent.
} 


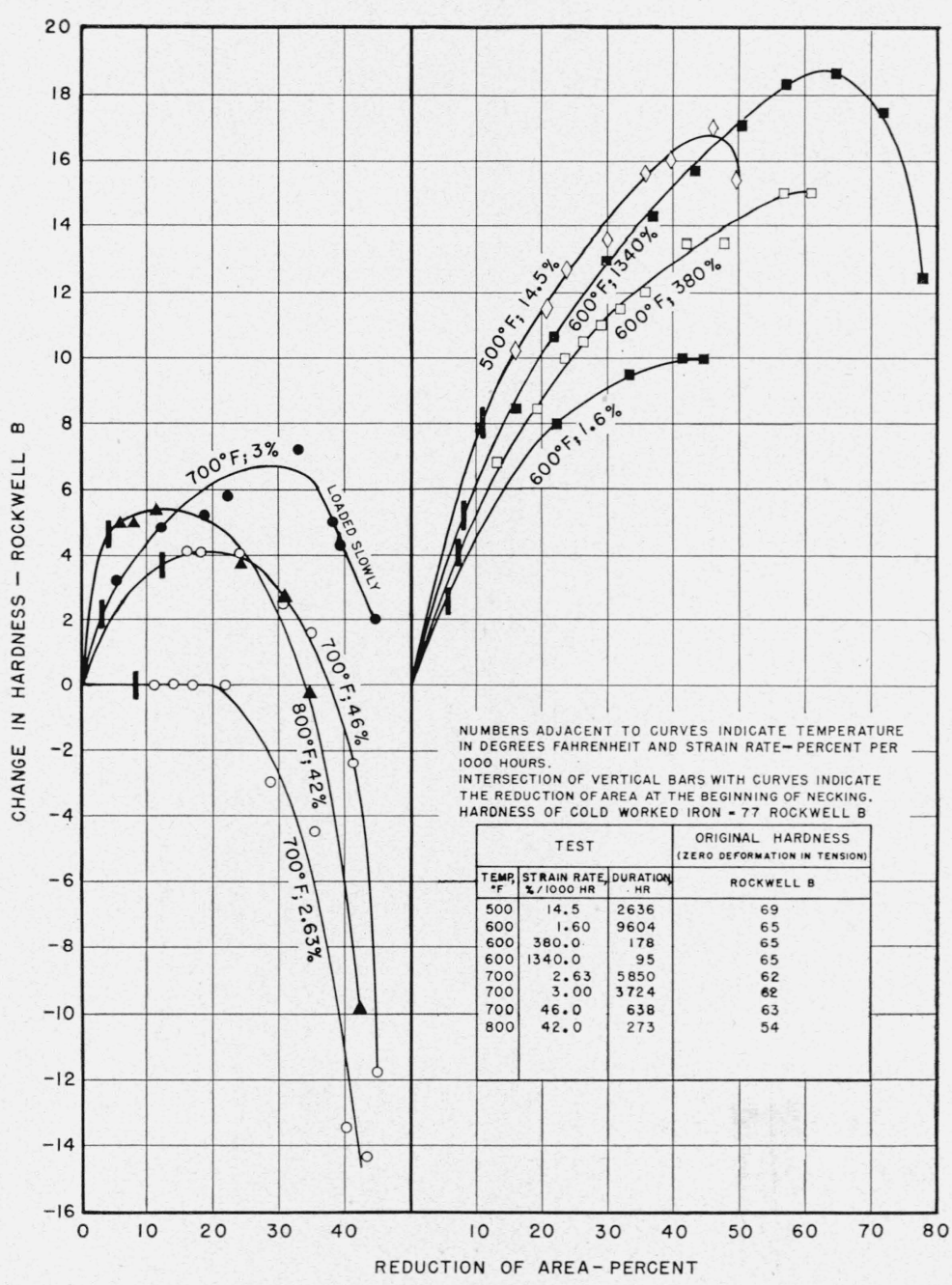

Figure 13. Effect of plastic deformation during creep at different temperatures and strain rates on change in hardness.

The hardness tests were made at room temperature on specimens after frecturing in creep. The creep during the third stage was mintained nealy

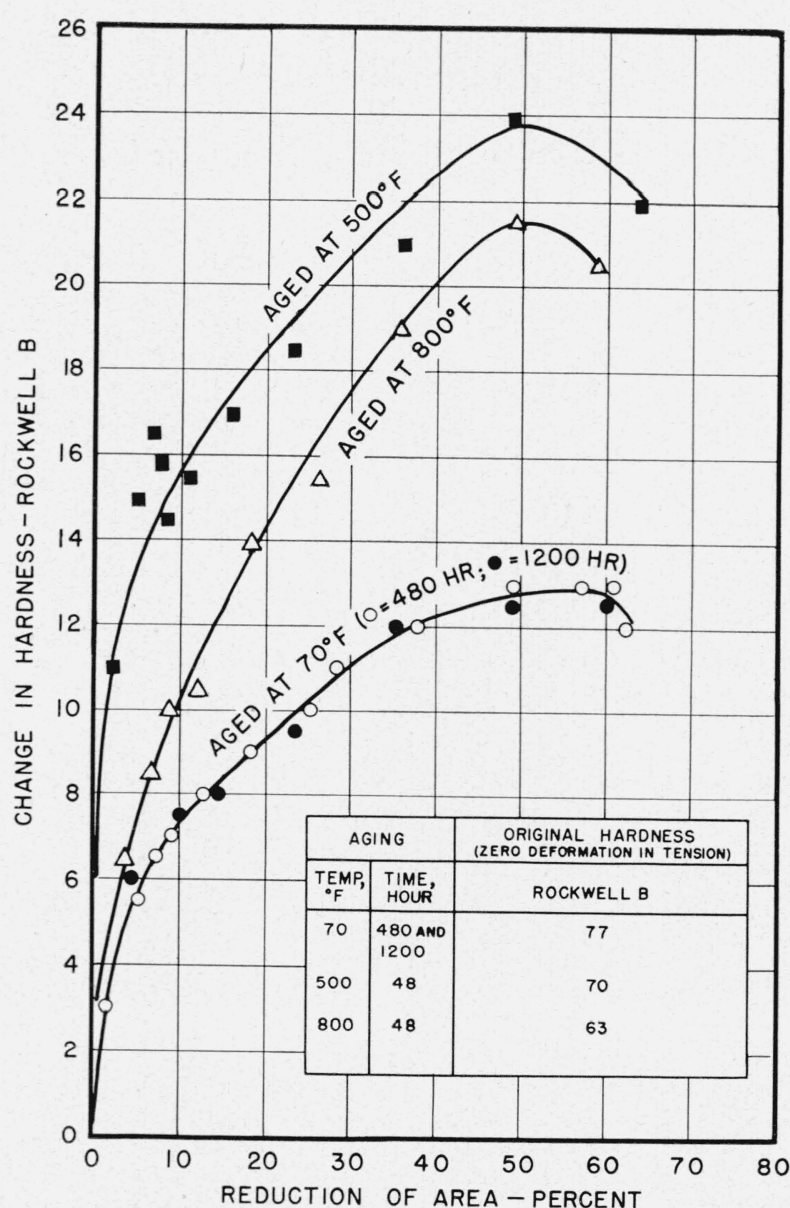

FIgURE 14. Effect of aging at different temperatures on change in hardness at room temperature of a specimen plastically deformed to fracture in tension at room temperature.

The tensile specimen was prepared from the bar as cold-drawn 13-percent reduction in area. The values for reduction of area as plotted in the figure do not include this 13 percent.

Washington, March 18, 1949. 